\title{
Incidence and Predictors of Anti-Retroviral Treatment (ART) Failure among Adults Receiving HIV Care at Zewditu Memorial Hospital, Addis Ababa, Ethiopia
}

\author{
Chalachew Sisay ${ }^{1 *}$, Alemayehu Bekele ${ }^{2}$, Abay Sisay $^{3}$, Hana Mekonen ${ }^{1}$, Kumera Terfa $^{1}$, Daniel Melese ${ }^{1}$ and Boja Dufera \\ ${ }^{1}$ Addis Ababa Public Health Research and Emergency Management, Addis Ababa, Ethiopia \\ ${ }^{2}$ Ethiopian Public Health Association, EPHA. Addis Ababa, Ethiopia \\ ${ }^{3}$ Addis Ababa University, College of Health Sciences, School of Clinical Laboratory Science. Addis Ababa, Ethiopia
}

\begin{abstract}
Background: Despite availability of antiretroviral therapy, HIV is responsible for 2.7 million new infections and 2.0 million deaths from worldwide. Anti-Retroviral treatment failure is not a commonly diagnosis in healthcare facilities in Ethiopia and there is dearth of information on the extent and predictors of treatment failure among adults receiving HIV care in the study setting. The aim of the current study is to assess the incidence and predictors of Anti-Retroviral Treatment (ART) failure among adults receiving HIV care at Zewditu Memorial Hospital, Addis Ababa, Ethiopia.
\end{abstract}

Methods: Facility based retrospective cohort study design was employed on archived data from 2011 to 2016. Data compilation checklist was developed from intake card and ART follow-up card. The collected data were coded and entered using Epi Info 7 and analysed using Statistical Packages for Social Science (SPSS) version 20 software.

Results: The overall incidence rate of ART treatment failure were 4.91 cases per person months follow up with 2.1, 0.24 and 0.13 immunological, clinical and virological treatment failure cases per 100 person years of follow-up respectively

Conclusion: The incidence of Anti-Retroviral Treatment failure was considerable among the study participants. The predictors for ART failure were WHO stage 3 at start, CD4 count at base line, disclosure and opportunistic infections. Comprehensive interventions have to be in place to tackle treatment failure among adults on ART through rendering optimum care focusing on adults with advanced WHO stage, lower CD4 count at baseline, opportunistic infections and people who did not disclose their HIV status.

Keywords: Adults; HIV; Incidence; Predictors; Anti-retroviral treatment failure

Abbreviations: ART: Antiretroviral Therapy; AIDS: Acquired Immuno Deficiency Syndrome; cART: Comprehensive Anti-retroviral Treatment; CI: Confidence Interval; HAART- Highly Active Anti-retroviral Therapy; HIV: Human Immunodeficiency Virus; MTCT: MotherTo-Child Transmission; PMTCT: Prevention Mother-To-Child Transmission; SNNP: South Nation Nationality People; SPSS- Statistical Packages for Social Science; WHO: World Health Organization

\section{Background}

Human Immune Deficiency Virus (HIV) is responsible for a worldwide pandemic and also the cause of Acquired Immune Deficiency Syndrome (AIDS). More than 36.7 million persons worldwide are living with HIV, of which 15.7 million (4\%) are women. In addition, there are 2.1 million new infections and 2.0 million deaths from AIDS worldwide, despite recent improvements in access to Antiretroviral Therapy (ART) [1].

The World Health Organization (WHO) estimated that nearly 11.7 million people living with human immunodeficiency virus (HIV) in low- and middle-income countries received antiretroviral therapy (ART) in 2013 [2]. Global ART scale-up has been made possible by the use of standardized and simplified treatment protocols and decentralized service delivery, with limited reliance on laboratory monitoring $[3,4]$. In order to enhance treatment monitoring, WHO recommended by 2013 that viral load measurements among people receiving ART be performed 6 months after initiating ART and every 12 months thereafter $[5,6]$.

Sub-Saharan Africa remains the region most heavily affected by HIV 1.9 million People living in sub-Sahara Africa become newly infected with HIV, bringing the total number of people living with HIV to 22.4 million. Moreover an estimated 1.4 million AIDS related deaths occur in sub-Sahara Africa. But the rate of new HIV infections and death has slightly declined as a result of improved access to ART [7].

In resource deprived countries ART Treatment failure is determined by clinical, immunological and/or virological failures and also patient monitoring system is dependent on clinic-immunological methods, though they lack sensitivity/specificity to detect virological failures of ART, which is the gold standard for ART treatment failure. Such circumstances, whether attributable to virologic failure, stopping ART or loss to follow-up, has been shown to increase morbidity and mortality [8].

Despite the fact that ART drugs are effective in improving the health status of HIV positive individuals up to undetectable viral load level. In Ethiopia, the past ten years, there have been significant achievements in the response to the human immunodeficiency virus (HIV) epidemic. One of the achievements was massive scale-up of

*Corresponding author: Chalachew Sisay, Addis Ababa public health research and emergency management, Addis Ababa, Ethiopia, Tel: 251924336220; E-mail: chalesisay19@gmail.com

Received November 24, 2017; Accepted December 06, 2017; Published December 13, 2017

Citation: Sisay C, Bekele A, Sisay A, Mekonen H, Terfa K, et al. (2017) Incidence and Predictors of Anti-Retroviral Treatment (ART) Failure among Adults Receiving HIV Care at Zewditu Memorial Hospital, Addis Ababa, Ethiopia. J AIDS Clin Res 8 : 749. doi: $10.4172 / 2155-6113.1000749$

Copyright: ( 2017 Sisay C, et al. This is an open-access article distributed unde the terms of the Creative Commons Attribution License, which permits unrestricted use, distribution, and reproduction in any medium, provided the original author and source are credited. 
antiretroviral treatment (ART) access to in the country has brought tremendous benefit to populations affected by HIV/AIDS [9].

After antiretroviral treatment (ART) initiation for the client monitoring and evaluation of blood viramia is one of the key activity of health care providers by the help of CD4 count, clinical evaluation and viral load measurement. However, based on CD4 count has poor predictor of virological failure and test targeted to monitor adherence in first-line anti-retroviral therapy (ART) [10].

ART failure is not a regularly diagnosis in most health care facilities in Ethiopia. Very few patients among the needy are started on second line ART regimens [11]. Previous studies have evaluated the patterns associated with switching from first line ART regimes to second line ART regimes; however, studies that evaluate the first line ART regime failures in limited resource settings like Ethiopia and Africa at large are scarce [12]. Even if many HIV positive clients accessed ART, there was a treatment failure, Studies show that the magnitude of ART treatment failure in the public health sector in Ethiopia ranges from $20.4 \%$ to $33.3 \%[13,14]$. By the end of June 2013 the number of people ever enrolled in chronic care reached 728,874 while the number ever started ART was 439,301 and 317,443 were currently receiving ART. Only $70.3 \%$ of individuals who ever started ART were currently on treatment indicating challenges in patients' retention [15-17].

Hence, this study was designed to disclose the incidence and predictors of ART treatment failure to inform healthcare professionals and the leadership of the health system to evaluate patients on ART in every visit for treatment failure and contributing factors to improve the quality of care and combat treatment failure to antiretroviral treatment.

\section{Method}

Facility based retrospective cohort study design, using facility records was employed. Data recorded from 2011 to 2016 were used to retrieve relevant information from patient ART intake card and follow up card and also from the hospital electronic database for ART program (Register Database) to address the objectives of the study. According to the annual report of the Addis Ababa City Administration Health Bureau for July 2015, there were a total of 125,994 HIV positive clients (94.4\% adults) who ever enrolled to ART services, among which 74,986 (94.8\% adults) had ever started ART and there were 53,677 (95.5\% adults) currently on ART. The city in 2015, 11 public hospitals, 77 Government health centers, 14 private hospitals and 9 Non Government clinics provided ART services in Addis Ababa. So the present study was conducted at Zewditu Memorial Hospital, which is one of referral public hospital in Addis Ababa, with strong HIV /AIDS care and treatment center.

The Hospital is one of the largest health facilities providing a comprehensive HIV care and treatment in Ethiopia. It was selected as the first pilot location for HIV programs and grew into a model program. In July 2003, Ethiopia's first ART program started at this health facility with support of CDC-Ethiopia and served HIV positive patients from around the country for a nominal fee. Through PEPFAR's support, the hospital began a free ART program in March 2005. Since the Hospital, one of the referral hospitals for the catchment sub city with wide geographical area, most patients have follow up in this hospital. There are a total of 10,672 patients enrolled to HIV care at Zewditu Memorial Hospital since 2003. From December 2011 to December 30, 2016 there were 3,184 HIV positive patients ever enrolled in chronic care who have baseline CD4 measured. Patients are then followed based on the National guideline. Hence, this study was conducted on data records of these clients (3184) enrolled to ART services from 2011 to 2016 in the hospital ART.

\section{Sample size determination and sampling technique}

Among the different predictors of treatment failure, baseline CD4 count $<500$ cells $/ \mathrm{mm}^{3}$ yield the maximum sample size. A power of $80 \%$, a 5\% level of significance and ratio of 1:2 (exposed: Unexposed) were assumed. Moreover, a $15.8 \%$ treatment failure among patients with baseline CD 4 count $>=500$ cells $/ \mathrm{mm}^{3}$ (exposure) and a $7.9 \%$ treatment failure among patients with baseline CD4 count 500 cells $/ \mathrm{mm}^{3}$ were assumed [18].

The sample size of this study was determined using the following formula

$$
\begin{aligned}
& n_{1}=\frac{\left(Z_{\beta / 2}+Z_{1-\beta}\right)^{2} \overline{p q}(r+1)}{r\left(p_{1}-p_{2}\right)^{2}} \\
& \text { And } n_{2}=r n_{1}
\end{aligned}
$$

where

$\mathrm{n}_{1}$ : number of exposed;

$\mathrm{n}_{2}$ : number of unexposed;

$1.96=$ value of the standard normal distribution corresponding to a significance level of $\alpha$ (1.96 for a 2 -sided test at the 0.05 level);

$0.84=$ value of the standard normal distribution corresponding to the desired level of power ( 0.84 for a power of $80 \%$ ).

$r=$ ratio of unexposed to exposed

$\mathrm{p}_{1}=$ proportion of exposed with disease and $\mathrm{q} 1=1-\mathrm{p} 1$

$\mathrm{p}_{2}=$ proportion of unexposed with disease and $\mathrm{q} 2=1-\mathrm{p}$

Based on the above assumptions, it was found that the sample size required was 531 with $12 \%$ of contingency (64) give 595 study participants included in study (Figure 1).

\section{Operational definitions}

Treatment failure: Is categorized as clinical, immunological and virological failure and defined as follows [19].

Clinical failure: New or recurrent WHO stage 4 condition OR new or recurrent WHO stage 3 with pulmonary TB and/or severe bacterial infections [19].

Immunological failure: Fall of CD4 count to baseline (or below) OR 50\% fall from on treatment peak value OR Persistent CD4 levels below 100 cells $/ \mathrm{mm}^{3}[19]$.

Virologic failure: Viral failure is defined by a persistently detectable viral load exceeding 1000 copies/mL (that is, two consecutive viral load measurements within 3 months interval with adherence support between measurements) after at least 6 months of starting a new ART regimen [20].

Poor adherence: Is defined in terms of total missed appointments described by greater than three days per month [20].

\section{Data quality control}

To ensure the quality of data, standard data compilation tool were designed by referring previous studies. Before data collection, the data collectors were get a one day orientation by principal investigators. The data collectors were Hospitals data clerks. There was a regular supervision to data collectors by the principal investigators to maintain the data quality. 


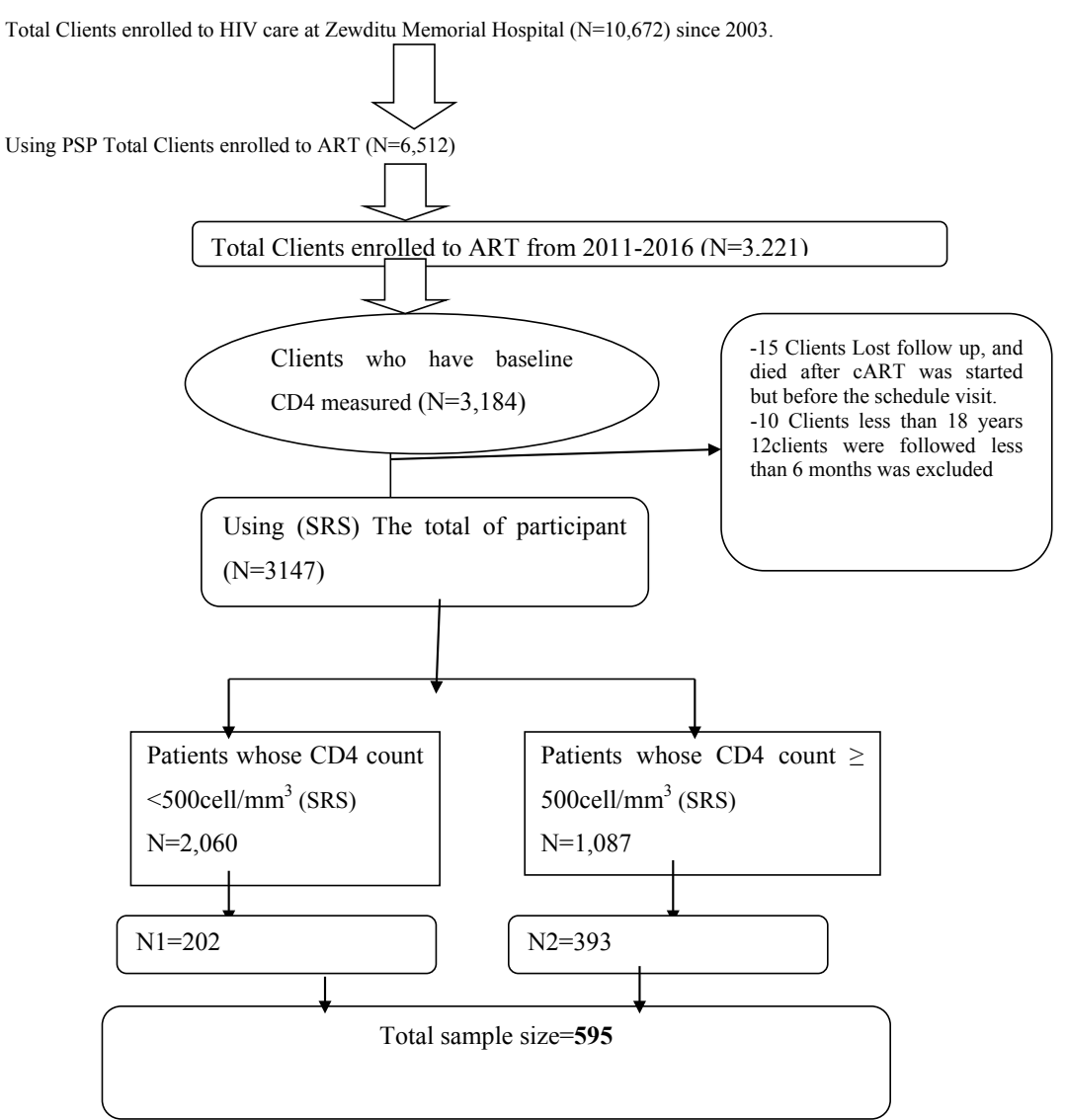

Figure 1: Sampling procedure of clients enrolled ART at Zewditu Memorial Hospital, January 2011-December 2016.

The required data was collected from electronic database for ART program (Register Database) by considering carefully all the variables stated in the tool with due attention to avoid any redundancy of the study participants. Completeness of the data was declared through periodic data collection. Finally data was analyzed employing appropriate statistical treatment following proper entry and cleaning.

\section{Data processing and analysis}

After the data was collected based on compilation tool developed entered to the excel sheet then cleaned, edited, coded and reentered and analyzed using SPSS version 20 statistical software package. Descriptive analysis using frequency and summary statistics was conducted to describe the study subject. Kaplan Meier survival analysis model were used to describe the time to treatment failure and Cox regression analysis has been used to determine the association between dependent variable and covariates with significant association ( $\mathrm{p}$ value $<0.05$ ). Hazard Ratio with $95 \%$ CI was used to determine the predictors of treatment failure.

\section{Results}

\section{Socio demographic characteristics study participants}

From January 2011 to December 2016, a follow up study using record review was conducted. A total of 595 patients receiving ART treatment were enrolled. Of these, 352 (59.2\%) were females. Most of the study participant $512(89.1 \%)$ were in the age group 25-49 years and the mean age at the start ART was $39.6 \pm 8.23$ years. Most of the study participant had secondary education 241 (40.5\%). Two hundred

\begin{tabular}{|l|c|c|c|c|}
\hline Characteristics & $\begin{array}{c}\text { Frequency } \\
\text { N=595 }\end{array}$ & (\%) & \multicolumn{2}{|c|}{ Lower Upper } \\
\hline Age & & & & \\
\hline $18-24$ & 19 & 3.2 & 1.8 & 4.7 \\
\hline $25-49$ & 512 & 89.1 & 83.2 & 88.9 \\
\hline$>=50$ & 64 & 10.8 & 8.2 & 13.3 \\
\hline Sex & & & & \\
\hline Female & 352 & 59.2 & 55.7 & 63.4 \\
\hline Male & 243 & 40.8 & 36.6 & 44.3 \\
\hline Marital status & & & & \\
\hline Never married & 173 & 29.5 & 26.0 & 33.7 \\
\hline Married & 233 & 39.7 & 35.4 & 43.8 \\
\hline Divorced & 115 & 19.6 & 16.2 & 22.5 \\
\hline Widowed & 66 & 11.2 & 8.7 & 14.0 \\
\hline Educational status & & & & \\
\hline No education & 65 & 11.1 & 8.3 & 13.6 \\
\hline Primary & 217 & 37.0 & 32.9 & 40.6 \\
\hline Secondary & 241 & 41.1 & 37.5 & 45.2 \\
\hline Tertiary & 64 & 10.9 & 8.3 & 13.3 \\
\hline Occupation/ & & & & \\
\hline Employment status & & & & 68.7 \\
\hline Employed & 359 & 64.6 & 60.6 & 39.4 \\
\hline Unemployed & 197 & 35.4 & 31.3 & \\
\hline Table 1: Basedine & & & & \\
\hline
\end{tabular}

Table 1: Baseline socio-demographic characteristics of adults enrolled for ART at Zewditu Memorial Hospital, from January 2011 to December 2016 (N=595).

thirty three (39.2\%) were married while based on occupational status of participant three hundred fifty nine (64.6\%) were employed (Table 1$)$. 


\section{Baseline clinical characteristics study participant}

The immunological, virological and clinical failures were $15.3 \%$, $1.8 \%$ and $4.4 \%$ respectively. Based on WHO staging treatment failure observed within the group found, so that patients found WHO stage 1 is $17(13.3 \%)$, stage 2 as $34(26.6 \%)$, stage 3, $58(45.3 \%)$ and stage 4 ,

\begin{tabular}{|c|c|c|c|c|}
\hline \multirow[t]{3}{*}{ ( $N=595)$ Characteristics } & \multirow[t]{3}{*}{$\begin{array}{l}\text { Frequency } \\
\mathrm{N}=595\end{array}$} & \multirow[t]{3}{*}{$(\%)$} & \multicolumn{2}{|c|}{$\begin{array}{l}\text { Bootstrap for } \\
\text { percent }\end{array}$} \\
\hline & & & \multicolumn{2}{|c|}{$\begin{array}{l}\text { 95\% Confidence } \\
\text { Interval }\end{array}$} \\
\hline & & & \multicolumn{2}{|c|}{ Lower Upper } \\
\hline \multicolumn{5}{|l|}{ Regiment started } \\
\hline $1 \mathrm{a}=\mathrm{d} 4 \mathrm{t}-3 \mathrm{TC}-\mathrm{NVP}$ & 17 & 2.9 & 1.5 & 4.2 \\
\hline $1 \mathrm{~b}=\mathrm{d} 4 \mathrm{t}-3 \mathrm{TC}-\mathrm{FEV}$ & 9 & 1.5 & 0.7 & 2.7 \\
\hline 1c=AZT-3TC-NVP & 36 & 6.1 & 4.2 & 7.7 \\
\hline 1d=AZT-3TC-EFV & 31 & 5.2 & 3.4 & 7.1 \\
\hline $1 \mathrm{e}=\mathrm{TDF}-3 \mathrm{TC}-\mathrm{EFV}$ & 436 & 73.3 & 69.7 & 77.0 \\
\hline $1 \mathrm{f}=\mathrm{TDF}+3 \mathrm{TC}+\mathrm{NVP}$ & 58 & 9.7 & 7.5 & 12.4 \\
\hline $1 \mathrm{~g}=\mathrm{ABC}+3 \mathrm{TC}+\mathrm{EFV}$ & 4 & 0.7 & 0.2 & 1.3 \\
\hline $1 \mathrm{~h}=\mathrm{ABC}+3 \mathrm{TC}+\mathrm{EFV}$ & 4 & 0.7 & 0.2 & 1.4 \\
\hline \multicolumn{5}{|l|}{ WHO stage } \\
\hline Stage I & 343 & 58.2 & 54.0 & 62.0 \\
\hline Stage II & 91 & 15.4 & 12.6 & 18.7 \\
\hline Stage III & 118 & 20.0 & 16.8 & 23.1 \\
\hline Stage IV & 37 & 6.3 & 4.4 & 8.3 \\
\hline \multicolumn{5}{|l|}{ Functional status } \\
\hline Working & 487 & 83.3 & 80.5 & 86.2 \\
\hline Ambulatory & 70 & 12.0 & 9.4 & 14.5 \\
\hline Bedridden & 28 & 4.8 & 3.2 & 6.5 \\
\hline \multicolumn{5}{|c|}{ Duration on ART in months } \\
\hline $6-12$ & 5 & 0.8 & 0.2 & 1.7 \\
\hline $13-25$ & 22 & 3.7 & 2.2 & 5.4 \\
\hline $26-48$ & 50 & 8.4 & 6.2 & 10.8 \\
\hline $49-61$ & 41 & 6.9 & 4.9 & 9.1 \\
\hline$>62$ & 477 & 80.2 & 76.5 & 83.2 \\
\hline \multicolumn{5}{|c|}{ CD4 count at baseline (cells $/ \mathrm{mm}^{3}$ ) } \\
\hline $0-49$ & 83 & 13.9 & 11.3 & 16.8 \\
\hline $50-99$ & 119 & 20.0 & 16.8 & 23.2 \\
\hline 100-199 & 139 & 23.4 & 19.8 & 26.7 \\
\hline $200-349$ & 202 & 33.9 & 30.1 & 38.2 \\
\hline $350-999$ & 52 & 8.7 & 6.4 & 11.3 \\
\hline \multicolumn{5}{|l|}{ Baseline Weight in $\mathrm{Kg}$} \\
\hline$<50$ & 101 & 17.6 & 14.4 & 20.7 \\
\hline$>50$ & 473 & 82.4 & 79.3 & 85.6 \\
\hline \multicolumn{5}{|l|}{ Disclosure } \\
\hline Not disclosed & 188 & 32.9 & 29.4 & 36.7 \\
\hline Disclosed & 384 & 67.1 & 63.3 & 70.6 \\
\hline
\end{tabular}

Table 2: Baseline clinical characteristics HIV infected patients enrolled for ART at Zewditu Memorial Hospital from January 2011 to December 2016. (N=595).
19 (14.8\%). Of the participants 495 (94.3\%) were no drug substitution similarly four hundred sixty two (78.2\%) were not drug switch. About three hundred forty three $(83.2 \%)$ were working in their functional status at the time of enrollment. The median baseline of CD4 counts were $157 \mathrm{cell} / \mathrm{mm}^{3}$ with inter quartile range (180: 27-289). The most common prescribed ART medication is TDF-3TC-EFV (1e) were 436 (73.3\%). The median waiting time on ART in the hospital was 45 months with the inter quartile range of 35 months. At baseline 343 (58.2\%) of the participants were found on WHO stage 1 . One hundred forty two (23.9\%) of study participant were diagnosed and confirmed HIV status more than five years. While One hundred forty nine (25\%) respondent were found on ART treatment follows up for more than four years. Four hundred seventy four (82.4\%) study participant were found greater than fifteen kilogram at baseline, in addition to this information, 384 (67.1\%) disclosed their status at baseline (Table 2).

\section{Treatment failure}

Among the 595 study participants, 465(78.5\%) were right censored (free of treatment failure). It was found that a total of 128 study participants $(21.5 \%)$ have indication of treatment failure with the occurrence rate was 4.91 cases per 1000 months follow up paired. Among the total 128 treatment failures $15.3 \%, 1.8 \%$ and $4.4 \%$ individual were categorized immunological, virological and clinical respectively. Among those patients who have treatment failure 19 (33.3\%) had viral load measurement at the end of one year treatment follow up. In the meantime the total of 11 immunologic failure (57.9\%) and 1 clinical (5.3\%) were viral load test was done and confirmed treatment failure. On the other hand patients who had ART treatment failure were 3(42.9\%), 9(72.5\%), 17(29.8), 4(19.0\%) and 95 (20.4\%) were transfer out, death, drop, lost, alive respectively (Table 3 ).

\section{Survival mean and median}

Using the Kaplan Meier survival analysis method, the mean survival time (the expected time to event) was found to be 50.52 months with 95\% CI $(48.30,52.73)$ while the median survival time was 53.54 months with $95 \%$ CI $(40.54,55.46)$. The overall incidence rate of treatment failure was 4.91 cases per 1000 person months of follow-up (Tables 4 and 5).

\section{Findings on survival functions}

The Log rank test showed that there was significant difference in survival times between the different categories of WHO stage, after recoding into two group, the comparison on the survival time of WHO stage 3 and 4 with WHO stage 1 and 2, until the first one year they have similar survival time. However, as time progressed, patients in WHO stage 3 and 4 at baseline had declined survival time. Adults in WHO stage land 2 at baseline had sustained the survival time up until year five (Figure 2).

The other relevant finding in this study patients were adherence to treatment, the survival function of treatment adherence status of patient shows that at time zero all patients have similar adherence

\begin{tabular}{|c|c|c|c|c|}
\hline Personal status category & Person time in months & Treatment failures & Treatment failure incidence rate & Case person-months \\
\hline Transfer out & 308.07 & 3 & 0.00973 \\
\hline Death & 1916.11 & 9 & 0.00469 \\
\hline Drop & 2078.58 & 17 & 0.00817 \\
\hline Lost & 871.09 & 4 & 0.00459 & 8.17 case per 1000 person months \\
\hline Alive & 20882.74 & 95 & 0.00474 & 4.59 case per 1000 person months \\
\hline Overall & 26056.59 & 128 & 0.00491 \\
\hline
\end{tabular}

Table 3: Person-time contributed by study participant and Incidence of treatment failure by status at the last visit in Zewditu Memorial Hospital in Addis Ababa, January 2011-Decmber 2016 
Citation: Sisay C, Bekele A, Sisay A, Mekonen H, Terfa K, et al. (2017) Incidence and Predictors of Anti-Retroviral Treatment (ART) Failure among Adults Receiving HIV Care at Zewditu Memorial Hospital, Addis Ababa, Ethiopia. J AIDS Clin Res 8: 749. doi: 10.4172/2155-6113.1000749

Page 5 of 9

\begin{tabular}{|c|c|c|c|c|c|c|c|c|c|}
\hline & $\mathbf{N}$ & Minimum & Maximum & Sum & Median & Mean & Inter quartile range (IQR) & Std. Error of the mean & Std. Deviation \\
\hline Age & 595 & 18 & 65 & 23569 & 40 & 39.6 & 11 & 0.34 & 8.24 \\
\hline Weight & 557 & 35 & 105 & 36333.12 & 65 & 65.2 & 19 & 0.57 & 13.47 \\
\hline Calculated months on ART & 595 & 6 & 139 & 26056.59 & 45 & 13.8 & 35 & 0.85 & 20.73 \\
\hline $\begin{array}{l}\text { Alive since HIVdiagnod } \\
\text { grouped in months }\end{array}$ & 595 & 6 & 150 & 34442.43 & 60 & 57.89 & 36 & 1.14 & 27.88 \\
\hline CD4 count at baseline & 595 & 10 & 898 & 109408 & 157 & 183.88 & 180 & 5.49 & 133.90 \\
\hline
\end{tabular}

Table 4: Survival characteristics of ART patients in Zewditu Memorial Hospital in Addis Ababa, 2011-2016.

\begin{tabular}{|c|c|c|c|c|c|c|c|c|}
\hline \multirow[t]{2}{*}{ VARABLES } & \multirow[t]{2}{*}{ Mean } & \multirow{2}{*}{$\begin{array}{l}\text { Std. Error of } \\
\text { the mean }\end{array}$} & \multicolumn{2}{|c|}{ 95\% Confidence Interval of the mean } & \multirow[t]{2}{*}{ Median } & \multirow{2}{*}{$\begin{array}{l}\text { Std. Error of } \\
\text { the median }\end{array}$} & \multicolumn{2}{|c|}{$95 \%$ Confidence Interval of the median } \\
\hline & & & Lower Bound & Upper Bound & & & Lower Bound & Upper Bound \\
\hline \multicolumn{9}{|c|}{ Body mass index } \\
\hline$<18 \mathrm{~kg} / \mathrm{m}^{2}$ & 47.670 & 1.399 & 44.928 & 50.412 & 52.000 & 2.139 & 47.807 & 56.193 \\
\hline $18.5-24.9 \mathrm{~kg} / \mathrm{m}^{2}$ & 45.096 & 1.833 & 41.503 & 48.689 & 45.260 & 3.203 & 38.982 & 51.538 \\
\hline $25-29.9 \mathrm{~kg} / \mathrm{m}^{2}$ & 45.614 & 2.638 & 40.443 & 50.786 & 49.000 & 2.810 & 43.492 & 54.508 \\
\hline $30-39.5 \mathrm{~kg} / \mathrm{m}^{2}$ & 76.175 & 4.780 & 66.807 & 85.544 & 67.000 & 1.070 & 64.903 & 69.097 \\
\hline Overall & 50.518 & 1.127 & 48.309 & 52.727 & 53.000 & 1.257 & 50.537 & 55.463 \\
\hline \multicolumn{9}{|l|}{ TB Baseline } \\
\hline Yes & 52.236 & 2.553 & 47.232 & 57.239 & 53.000 & 4.254 & 44.663 & 61.337 \\
\hline No & 49.749 & 1.231 & 47.336 & 52.162 & 53.000 & 1.261 & 50.528 & 55.472 \\
\hline Overall & 50.340 & 1.135 & 48.114 & 52.565 & 53.000 & 1.221 & 50.608 & 55.392 \\
\hline \multicolumn{9}{|c|}{ Years since HIV diagnosed (months ) } \\
\hline $6-12$ & 18.889 & 6.229 & 6.681 & 31.098 & 9.200 & 0.820 & 7.593 & 10.807 \\
\hline $12-24$ & 17.489 & 0.581 & 16.351 & 18.628 & 17.250 & 0.458 & 16.352 & 18.148 \\
\hline $24-36$ & 28.121 & 0.871 & 26.413 & 29.828 & 26.660 & 1.798 & 23.136 & 30.184 \\
\hline $36-48$ & 39.972 & 0.859 & 38.288 & 41.657 & 42.000 & 1.596 & 38.871 & 45.129 \\
\hline $48-60$ & 48.299 & 1.356 & 45.641 & 50.958 & 53.000 & 1.024 & 50.993 & 55.007 \\
\hline $60-72$ & 59.458 & 0.990 & 57.518 & 61.398 & 63.000 & 1.523 & 60.015 & 65.985 \\
\hline$>72$ & 70.610 & 2.567 & 65.579 & 75.642 & 67.000 & 1.964 & 63.151 & 70.849 \\
\hline Overall & 50.518 & 1.127 & 48.309 & 52.727 & 53.000 & 1.257 & 50.537 & 55.463 \\
\hline \multicolumn{9}{|c|}{ Duration on ART (in months) } \\
\hline $6-12$ & 23.682 & 6.109 & 11.709 & 35.655 & 11.000 & 1.101 & 8.842 & 13.158 \\
\hline $12-24$ & 26.455 & 2.198 & 22.146 & 30.764 & 18.220 & 0.687 & 16.874 & 19.566 \\
\hline $24-36$ & 36.340 & 1.357 & 33.681 & 39.000 & 32.200 & 0.310 & 31.592 & 32.808 \\
\hline $36-48$ & 45.307 & 0.713 & 43.910 & 46.704 & 45.120 & 0.952 & 43.254 & 46.986 \\
\hline $48-60$ & 59.202 & 0.992 & 57.258 & 61.146 & 55.000 & 0.343 & 54.327 & 55.673 \\
\hline$>60$ & 73.453 & 1.801 & 69.923 & 76.983 & 67.000 & 0.291 & 66.431 & 67.569 \\
\hline Overall & 50.518 & 1.127 & 48.309 & 52.727 & 53.000 & 1.257 & 50.537 & 55.463 \\
\hline
\end{tabular}

Table 5: Survival characteristics of group of variables on ART patient in Zewditu Memorial Hospital, Addis Ababa, 2011-2016.

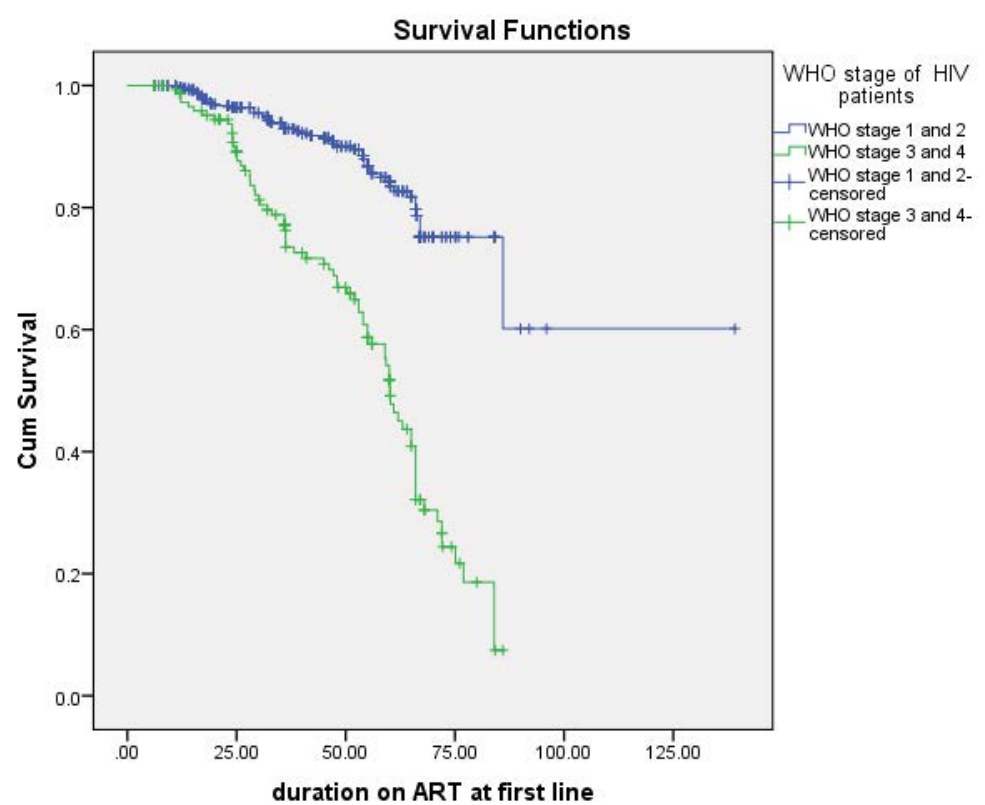

Figure 2: Survival functions of different groups of WHO stage of ART clients in Zewditu Memorial Hospital in Addis Ababa, January 2011-Decmber 2016. 
status while patients with poor adherence status to treatment as the time progress the odds of survival function declined while those with Good adherence status were sustained in the long paired (Figures 3 and 4) Patients at the beginning of ART started they have similar survival time until two years however when the time steps forward the survival staidly declined until six years (Figure 5).

\section{Predictors of treatment failure}

Cox regression analysis was done, among 595 study participant. In this study except marital status all other socio demographic variables including age, educational status and employment condition were found to be significant predictors of Anti Retro viral Treatment (ART) failure. Accordingly, being unemployed, being old age (age $\geq 50$ years ) and primary and secondary education level of HIV patient more likely hazard risk of anti-retro-viral treatment failure by $1.57,1.96,1.42$ and 1.27 times with 95\% CI (AHR (1.096,2.293)), (AHR (1.308,2.958)), (AHR $(1.010,2.022))$ and (AHR $(1.014,1.613))$, respectively (Table 3). Similarly, clinical characteristics including WHO stage at baseline,

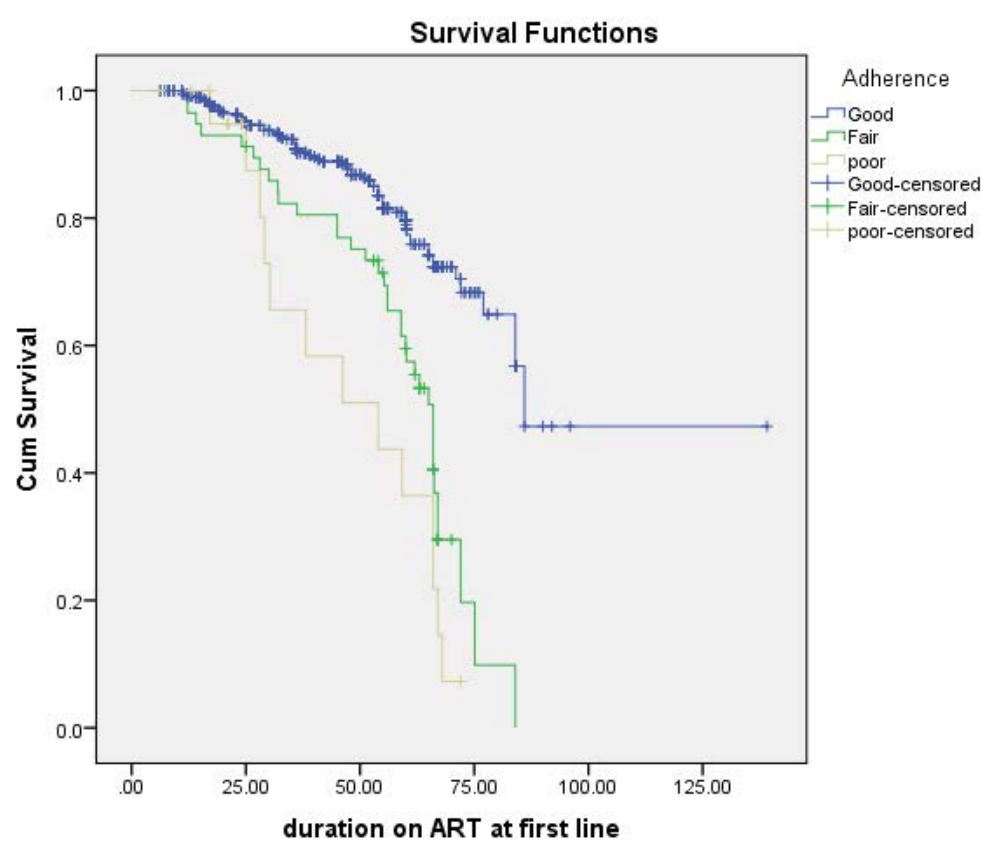

Figure 3: Survival functions of different groups of treatment adherence ART clients in Zewditu Memorial Hospital in Addis Ababa, January 2011 -Decmber 2016.

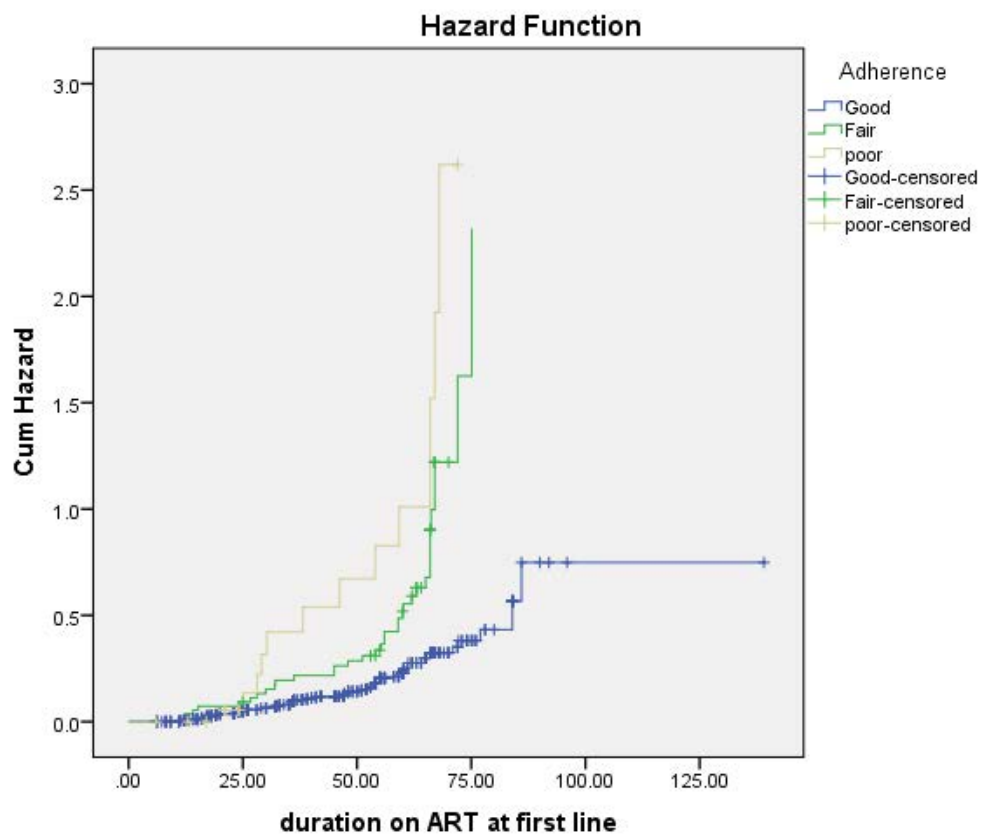

Figure 4: Hazard risk of different groups of treatment adherence of ART clients in Zewditu Memorial Hospital in Addis Ababa, January 2011 -Decmber 2016. 


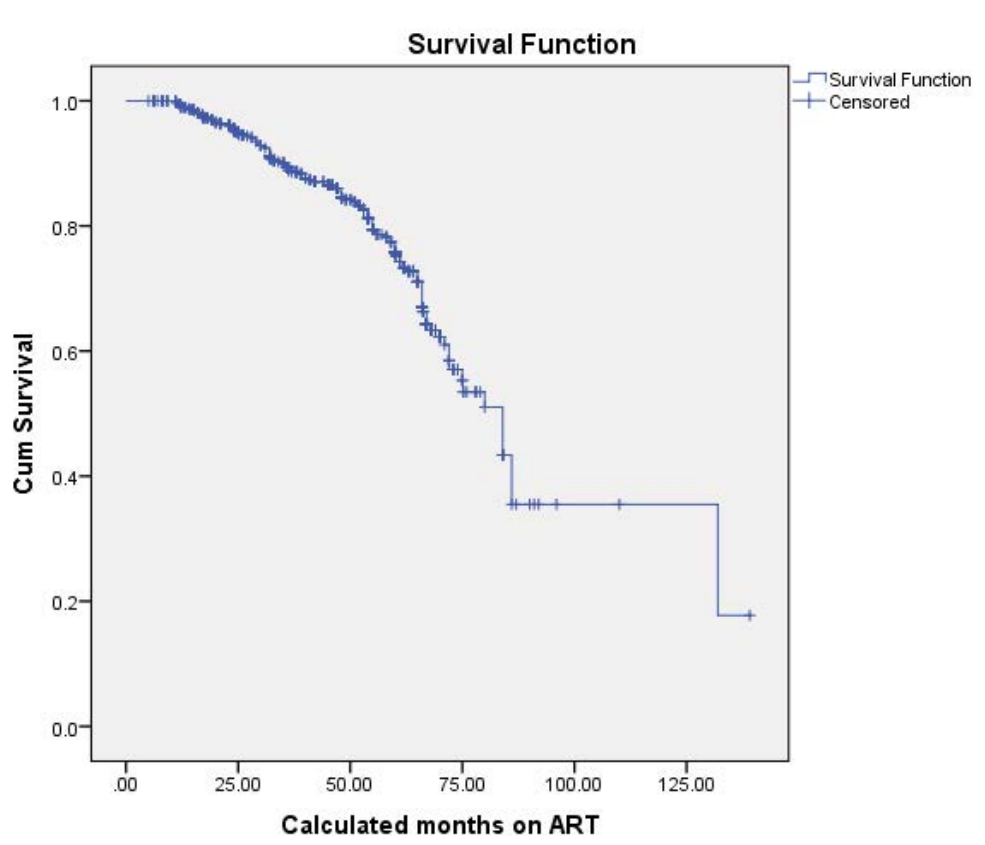

Figure 5: Survival functions of ART clients from six months of therapy to treatment failure in Zewditu Memorial Hospital in Addis Ababa, January 2011-December 2016

Disclosure, any opportunistic infection except TB, Adherence, CD4 count at baseline (cells $/ \mathrm{mm}^{3}$ ) and, had significant relationship with treatment failure as predictors.

Patients who had CD4 count $\left(0-49\right.$ cells $\left./ \mathrm{mm}^{3}\right)$ at baseline were 2.67 times more likely to have treatment failure than patients with CD4 count (350-999 cells $\left./ \mathrm{mm}^{3}\right)$ at $95 \%$ CI (AHR: $2.67 ; 95 \%$ CI (1.2975.515)).

ART clients who had not disclosed their HIV status to any one had more likely to develop risk of treatment failure as compared with ART customers who disclosed their status (AHR: 1.49; 95\% CI (1.1721.900)).

Patients who have any opportunistic infection except TB, have risk of treatment failure as compared with no any opportunistic infection at baseline (AHR: 0.642; 95\% CI (0.472-0.875).

Forty eight percent ( $48 \%$ ) of the treatment failure were detected patient who were found WHO stage 3 as compared to patients who were found WHO stage 1 (AHR: 0.52; 95\% CI (0.294-0.954). Similarly $48 \%$ of treatment failures was emanated from patients with fair adherence to the treatment as compared to Good treatment adherence (AHR: 0.52; (0.351-0.774) (Table 6).

\section{Discussion}

This study was designed to assess the incidence and predictors of ART treatment failure in Zewditu Memorial Hospital, Addis Ababa, Ethiopia from January 2011-December 2016.

The overall Incidence of treatment failure in the current study is 4.91 cases per 1000 person months of follow up. This is by far lower than the finding of another study conducted in private health facilities in Addis Ababa. This could be due to variation in the service quality including monitoring HIV Viral load is often not performed, the assays are costly and require sophisticated, expensive laboratory equipment and trained technicians private health facilities quality [18,21,22]. The incidence of immunological, virological and clinical failure in this study is $2.1,0.24$ and 0.13 per 100 person years of follow-up respectively. As the sensitivity and specificity of immunologic and clinical failures were discussed to be low despite these limitations, in recent year the importance of HIV viral load testing is increasingly recognized; implying the relevance of diagnosing failure using viral load determination technique to obtain better yield of patients' status. Thus the assessment of progress in clinical condition has to be further accompanied by viral load tests to confirm true treatment failure and to take optimal decision of switching and avoiding misclassification [23]. However, viral load determination is not well accessible in resource meager settings like Ethiopia. Likewise, only 11 patients with immunologic failure (57.9\%) and 1 clinical (5.3\%) were further tested for viral load. Contrasting the findings from a study conducted in Kenya [24], where the clinical failure exceeded the virological and immunological failures, the results from this study showed that the treatment failure as defined by immunological criteria was high (15\%); followed by the clinical failure (4.4\%) and by virological failure (1.8\%).

The hazard of developing treatment failure among patients age were $\geq 50$ years was higher compared to age 18-24 years this is in contrast to the study conducted Myanmar [25]. This may be due to poor adherence, the differences in the medical attention given to the patients with advanced age.

Patients who had CD4 count greater than 50 cells $/ \mathrm{mm}^{3}$ and weight greater than $50 \mathrm{Kg}$ at baseline the hazard of treatment failure is $16.2 \%$ and $21.6 \%$, respectively this is aligned with study conducted in Kenya [26].

The mean survival time (the expected time to event) in current study is 50.20 months however median survival time was similar to the 53.54 months study conducted in Addis Ababa [18]; the difference may be the health care practices and care that given matters.

By conducting Multivariate Cox analysis five significant predictors of treatment failure obtained. Among the predictors like opportunistic infection, adherence, WHO stage at baseline, CD4 count in cells $/ \mathrm{mm}^{3}$ at baseline and disclosure status were statistically significant. 
Page 8 of 9

\begin{tabular}{|c|c|c|c|c|}
\hline Covariate & Treatment failure (\%) & $\begin{array}{l}\text { Free of treatment } \\
\text { failure }(\%)\end{array}$ & Crude hazard risk $(95 \% \mathrm{Cl})$ & Adjusted hazard risk $(95 \% \mathrm{Cl})$ \\
\hline \multicolumn{5}{|l|}{ Age } \\
\hline $18-24$ & 0 & $12(2.4)$ & 1 & \\
\hline $25-49$ & $72(76.6)$ & $377(75.2)$ & $0.955(0.537-1.699)$ & $1.730(0.945-3.168)$ \\
\hline$>=50$ & $22(23.4)$ & $112(22.4)$ & $0.537(0.300-0997)$ & $1.279(1.014-1.613)^{\star \star}$ \\
\hline \multicolumn{5}{|l|}{ Education } \\
\hline Not educated & $20(21.5)$ & $47(9.5)$ & $0.528(0.354-0.787)^{*}$ & $1.171(0.825-1.663)$ \\
\hline primary & $40(43.0)$ & $178(35.8)$ & $0.611(0.455-0.821)^{*}$ & $1.429(1.010-2.022)^{\star *}$ \\
\hline Secondary & $30(32.3)$ & $211(42.5)$ & $0.725(0.544-0.966)^{*}$ & $1.967(1.308-2.958)^{\star *}$ \\
\hline tertiary & $3(3.2)$ & $61(12.2)$ & 1 & \\
\hline Unemployed & $34(34.0)$ & $163(34.6)$ & $1.583(1.096-2.287)^{\star}$ & $1.575(1.096-2.293)^{* \star}$ \\
\hline \multicolumn{5}{|c|}{ Opportunistic infection (OI) } \\
\hline None & $65(52.8)$ & $400(87.9)$ & 1 & 1 \\
\hline Any Ol except TB & $37(30.1)$ & $45(9.9)$ & $1.720(0.968-3.056)^{*}$ & $0.642(0.472-0.875)^{\star *}$ \\
\hline TB (all types) & $21(17.1)$ & $10(2.2)$ & $1.048(0.555-1.979)$ & $0.604(0.340-1.073)$ \\
\hline \multicolumn{5}{|l|}{ Adherence } \\
\hline Good & $75(61)$ & $409(93.0)$ & 1 & \\
\hline Fair & $35(28.5)$ & $22(5.0)$ & $0.406(0.245-0.600)^{*}$ & $0.522(0.351-0.774)^{\star *}$ \\
\hline Poor & $13(10.3)$ & $9(2.0)$ & $0.541(0.279-1.047)$ & \\
\hline \multicolumn{5}{|c|}{ WHO stage at baseline } \\
\hline 1 & $17(13.3)$ & $326(70.7)$ & 1 & \\
\hline 2 & $34(26.6)$ & $57(12.4)$ & $0.088(0.046-0.168)^{*}$ & $0.085(0.044-0.166)$ \\
\hline 3 & $58(45.3)$ & $60(13.0)$ & $0.544(0.309-0.096)^{*}$ & $0.529(0.294-0.954)^{\star \star}$ \\
\hline 4 & $19(14.6)$ & $18(3.9)$ & $0.776(0.461-1.308)$ & $0.730(0.423-1.260)$ \\
\hline \multicolumn{5}{|l|}{ Baseline TB } \\
\hline Yes & $64(50.8)$ & $88(19.3)$ & 1 & \\
\hline No & $62(49.2)$ & $369(80.7)$ & $0.386(0.272-.549)$ & \\
\hline \multicolumn{5}{|c|}{ CD4 count at baseline (cells $/ \mathrm{mm}^{3}$ ) } \\
\hline $0-49$ & $40(31.2)$ & $43(9.2)$ & $2.879(1.399-5.924)^{*}$ & $2.673(1.297-5.515)^{\star *}$ \\
\hline $50-99$ & $42(32.8)$ & $77(16.5)$ & $1.531(0.743-3.154)$ & $1.223(0.592-2.529)$ \\
\hline 100-199 & $20(15.6)$ & $119(25.5)$ & $0.816(0.371-1.795)$ & $0.971(0.439-2.144)$ \\
\hline $200-349$ & $17(13.3)$ & $185(39.6)$ & $0.369(0.164-0.829)^{\star}$ & $0.393(0.171-0.901)^{\star \star}$ \\
\hline 350-999 & $9(7.0)$ & $43(9.2)$ & 1 & \\
\hline \multicolumn{5}{|l|}{ Disclosure } \\
\hline Not Disclosure & $84(67.2)$ & $104(23.3)$ & $1.289(1.040-1.598)$ & $1.492(1.172-1.900)^{* *}$ \\
\hline Disclosure & $41(32.8)$ & $343(76.7)$ & 1 & \\
\hline
\end{tabular}

** indicates $p<0.05$

Table 6: Cox-regression analysis showing predictors of ART treatment failures in Zewditu Memorial Hospital from January 2011 to December 2016.

In the current study, WHO stage 3 at the base was found to increase the hazard risk of treatment failure. This is similar with studies conducted in Ethiopia and Mozambique [18,23].

As for the disclosure status, patients who do not disclose their HIV status were more likely to have treatment failure than those who disclose. This is in agreement with the findings of a study conducted at St. Luke and Tulu Bolo Hospitals, South West Shoa Zone, Oromia $[18,27]$. However, it is dissimilar with the findings from a study in Tanzania [23]. This may be explained by differences in perceived and enacted stigma and discriminatory attitudes between the two settings.

\section{Limitation of the Current Study}

Lack of completeness of independent variables might have affected the findings. In addition to this some other important behavioral and background data like educational, disclosure, individual income were not captured in the ART registers and/or follow up charts and electronic databases.

\section{Conclusion}

The treatment failure incidence rate in Zewditu Memorial hospital was considerable. The independent predictors of treatment failure are adherence, WHO stage 3 at baseline, CD4 count in cells $/ \mathrm{mm}^{3}$ at baseline and disclosure status. Early Antiretroviral treatment failure detection is one of critical key improvement area of the health care providers with close follow up of ART clients and identifying the predictor factors of failure.

\section{Recommendation}

Based on the findings obtained, the following recommendations were put forward in the study area.

1. To solve treatment failure can be minimized by routinely following the patients viral load all HIV patients however; those patients were found the potential predictors of treatment failure including low CD4 count, WHO stage 3, opportunistic infection and not disclosure. 
2. The clinicians should follow treatment failures early using the gold standard, viral load test, before and after switching second line generation.

3. Finally the ART treatment failure incidence rate should be researched in all other hospitals.

\section{Ethics Approval and Consent to Participant}

Ethical clearance was obtained from Addis Ababa public health research and emergency management core process Ethics and Research Committee and permission were obtained from Zewiditu Memorial hospital where data is going to be collected.

\section{Availability of Data and Material}

The data sets during and/or analyzed during the current study available from the corresponding author on reasonable request.

\section{Authors' Contributions}

Chalachew sisay, Alemayehu Bekele conceived and designed the study and collected data, performed analysis, interpretation of data and also critically reviewed of this manuscript. Abay Sisay, Hana Mekonon, Kumera Terfa, Danie Melese and Boja Dufera support data collection, perform analysis, interpretation of data and also critically reviewed of this manuscript.

\section{Acknowledgment}

We are grateful to Zewditu Memorial Hospital for providing the data and the Ethiopian public Health Association for technically supporting the study.

\section{References}

1. http://www.who.int/hiv/pub/arv/global-AIDS-update-2016_en.pdf?ua=1

2. http://www.who.int/hiv/pub/progressreports/update2014/en/

3. http://www.who.int/hiv/pub/amds/access-arv-2014/en/

4. Gilks CF, Crowley S, Ekpini R, Gove S, Perriens J, et al. (2006) The WHO public-health approach to antiretroviral treatment against HIV in resourcelimited settings. Lancet 368: 505-510.

5. http://www.who.int/hiv/pub/guidelines/arv2013/down load/en/

6. Keebler D, Revill P, Braithwaite S, Philips A, Blaser N, et al. (2014) Costeffectiveness of different strategies to monitor adults on antiretroviral treatment: A combined analysis of three mathematical models. Lancet Glob Heal 2: e35-e43

7. http://www.unaids.org/en/HIVdate/2006/Global Report/default.ads

8. Zaccarelli M, Tozzi V, Lorenzini P, Trotta MP, Forbic F, et al. (2005) Multiple drug class-wide resistance associated with poorer survival after treatment failure in a cohort of HIV-infected patients. AIDS 19: 1081

9. Lundgren JD, Mocroft A, Gatell JM, Ledergerber B, Monforte A, et al. (2002) A clinically prognostic scoring system for patients receiving highly active antiretroviral therapy: Results from the Euro SIDA study. J Infect Dis 185: 178-187.
10. Gross R, Bilker WB, Friedman HM, Strom BL (2001) Effect of adherence to newly initiated antiretroviral therapy on plasma viral load. AIDS 15: 2109-2117.

11. http://files.unaids.org/en/media/unaids/contentassets/documents/data-andanalysis/tools/spectrum/Ethiopia2012report.pdf

12. Elke K, Yirga A, Katherine D, Peter G, Tesfaye A, et al. (2012) Implications of adopting new WHO guidelines for antiretroviral therapy initiation in Ethiopia. Bull World Health Organ 90: 659-663.

13. Anteneh T (2010) Predictors of immunologic failure in treatment naive HIV infected patients who start highly active anti-retroviral therapy (HAART) in Addis Ababa Ethiopia. MPH Thesis, Addis Continental Institute of Public Health.

14. Selamawit E (2009) First line antiretroviral treatment failure and factors associated with it in Addis Ababa. MPH Thesis, Addis Ababa University.

15. http://apps.who.int/medicinedocs/documents/s17820en/s17820en.pdf

16. Federal Ministry of Health $(\mathrm{MOH})(2007)$ Guideline for implantation of the antiretroviral therapy program in Ethiopia. $\mathrm{MOH}$, Addis Ababa, Ethiopia.

17. FHAPCO (2005) EFY Multisectoral HIVIAIDS Response Annual Report. Draft document, Ethiopia.

18. TeshomeYimer Y, Yalew AW (2015) Magnitude and predictors of anti-retrovira treatment (ART) failure in private health facilities in Addis Ababa, Ethiopia PLOS ONE 10 .

19. http://aidsinfo.nih.gov/guidelines

20. Bacha T, Tilahun B, Worku A (2012) Predictors of treatment failure and time to detection and switching in HIV infected Ethiopian children receiving first line anti-retroviral therapy. BMC Infect Dis 12: 197

21. Crowe SM, Turnbull SP, Oelrichs R, Dunne AL (2003) Monitoring human immunodeficiency virus infection in resource-constrained countries. Clin Infect Dis 37: S25-S35.

22. Fiscus SA, Cheng B, Crowe SM, Demeter L, Jennings C, et al. (2006) HIV-1 viral load assays for resource-limited settings. PLoS Med 3: e417.

23. Andrew FA, Francisco M, Ray WS, Mauro S, Charity A, et al. (2011) Fouryear treatment outcomes of adult patients enrolled in mozambique's rapidly expanding antiretroviral therapy program. PLoS One 6: e18453.

24. Sollis KA, Smit PW, Fiscus S, Ford N, Vitoria M, et al. (2014) Systematic review of the performance of HIV viral load technologies on plasma samples. PLoS One 9: e85869.

25. Colebunders R, Moses KR, Laurence J, Shihab HM, Semitala F, et al. (2006) A new model to monitor the virological efficacy of antiretroviral treatment in resource-poor countries. Lancet Infect Dis 6: 53-59.

26. Nicolai L, Niels O, Gitte K, Laursen A, Pedersen C, et al. (2005) Declining risk of triple-class antiretroviral drug failure in Danish HIV-infected individuals. AIDS 19: 815-822.

27. Bayou B, Sisay A, Kumie A (2015) Assessment of the magnitude and associated factors of immunological failure among adult and adolescent HIV infected patients in St. Luke and Tulubolo Hospital, Oromia Region, Ethiopia Pan Afr Med J 21: 291 